\title{
Evaluation of the demographic profile of patients with implant-supported fixed dental prostheses:
} A retrospective clinical study

\author{
Fatih Demirci'®i, Abdulsamet Tanık² \\ ${ }^{1}$ İnonü University, Faculty of Dentistry, Department of Prosthodontics, Malatya, Turkey \\ ${ }^{2}$ Adıyaman University, Faculty of Dentistry, Department of Periodontology, Adıyaman, Turkey
}

\section{Correspondence:}

\section{Dr. Abdulsamet TANIK}

Adiyaman University, Faculty of

Dentistry, Department of

Periodontology, Adiyaman, Turkey.

E-mail:samet.120a@gmail.com

Received: 1 February 2021

Accepted: 25 August 2021

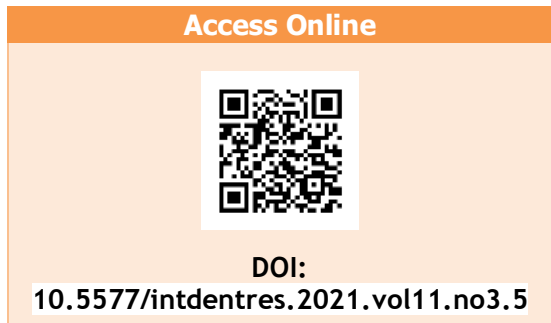

\section{Introduction}

Dental implants are widely and frequently used for the treatment of partial and total edentulism in dentistry. Dental implant treatment is extremely effective for the rehabilitation of missing teeth. However, for the successful placement and use of dental implants, a sufficient amount and quality of the rate

\begin{abstract}
Aim: In this study, the aim is to evaluate the demographic profile as well as clinical aspects of patients who received implant-supported fixed dental prostheses (FDPs) between 2016 and 2019 years.

Methodology: Among 150 patients with implant-supported FDPs, 120 contacted patients were included in the study. The patients were examined in terms of gender, age groups, edentulism, restoration type, implant location, implant survival rate, and abutment type by using the computer software. Data results were analyzed by descriptive statistical methods.

Results: Three hundred and six dental implants were evaluated in a total of 120 patients, 55 men, and 65 women. The average age of the patients was $49.61 \pm 11.84$, and the most common dental implant application was in the 51-60 age group. Dental implants were frequently applied to the posterior mandible, and $31.9 \%$ of them were applied to patients in the 51 60 age group. A $94.8 \%$ implant survival rate was observed. A significant difference was found among age groups with laser-sintered metal-ceramics (LSMC) and all-ceramics $(p<0.05)$. LSMC was the most common type of restoration, and straight abutments were frequently used.

Conclusion: Although the survival rate of dental implants is high, implants with a medium length and diameter are frequently used. The type of restoration, type of abutment, and implant location in implantsupported FDPs vary depending on the age and gender of the patients.
\end{abstract}

Keywords: angled abutment, dental implant, implant prosthesis, survival

How to cite this article: Demirci F, Tanık A. Evaluation of the demographic profile of patients with implant-supported fixed dental prostheses: A retrospective clinical study. Int Dent Res 2021;11(3):165-71. https://doi.org/10.5577/intdentres.2021.vol11.no3.5 alveolar bone structure are crucial to render primary stability $(1,2)$.

Detailed clinical and radiological evaluation, determination of risk factors, and follow-up of patients to be treated with dental implants increase the success of dental implants. Risk factors that affect the success of dental implant applications also should be considered. It is crucial to consider the risk factors associated with the age, gender, systemic health status 
of patients, smoking and alcohol use, condition of the alveolar bone, and implant properties (3).

Periodontal diseases are one of the key factors that affect the success of implants and long-term oral survival as well as cause the loss of permanent teeth (4). In addition, peri-implant tissue health, prosthetic parameters, aesthetics, and patient satisfaction criteria are considered to be factors for the success of dental implants. In recent years, the accepted general view regarding the success of dental implants is that the implant should be aesthetically and functionally satisfactory. In addition, osseointegration criteria are the most important success criteria (5). Most patients prefer implant-supported prostheses due to their ease of use, naturalness, and psychological sense of integrity in patients $(1,4)$.

Prospective and retrospective studies examined dental implant applications in the long term, which were predominantly related to the success of dental implants, peri-implantitis treatment, and other dental implant complications $(6,7)$. In this study, in addition to studies evaluating demographic factors related to dental implants, implant failure rates are determined, and the most appropriate treatment plan for the comfort of the clinician and patient is discussed. In addition, dental implant indications, lengths/diameters of dental implants, implantsupported fixed restoration type, abutment type, and implant loss considering the demographic characteristics of the patients who underwent dental implants are analyzed.

In dental implant applications, minimizing implant failure and increasing the lifespan of dental implants is key to patients and clinicians. Therefore, clinical and experimental studies are required, which can increase the success in this field via the introduction of objective criteria that have taken their place in literature. This retrospective study aimed to report demographic characteristics of patients who had dental implants and the survival rate of dental implants in our clinic between 2016 and 2019.

\section{Materials and Methods}

This study was approved by Adiyaman University Ethics Committee (Protocol Number: 2020/3-13). Next, a list of patients with a completed treatment code in the file for the dental implant and implant-supported FDPs (cast metal-ceramic, LSMC, zirconia-ceramic, and all-ceramic) was collected from the electronic database (Turcasoft DBYS, Turcasoft software, Samsun, Turkey), added to a spreadsheet (Excel, Microsoft Corp.), and compiled. Inclusion criteria included patients with sufficient knowledge of the electronic file or scanned attached documents related to the performed procedure, and radiographic and clinical outcomes after insertion and survival or failure. A total of 120 patients, 55 males and 65 females, who could be contacted from 150 patients satisfying these conditions, were evaluated clinically and radiographically at the control appointments. Thirty patients were excluded from the study as they could not be contacted. The patients were informed about the content of the study, and consent forms were obtained from the patients indicating their willingness to participate in the study.

A total of 306 endosseous dental implants were applied to 120 patients with Bredent (Bredent Group GmbH \& Co.KG, Senden, Germany) and Implance (AGS Medikal, Trabzon, Turkey) dental implant systems at the Adiyaman University, Faculty of Dentistry between 2016 and 2019. Age groups (18-30, 31-40, 41-50, 51-60, and 61-80), gender, edentulous condition, implant location, total number of implants applied to maxilla and mandible, diameters and lengths of implants, and additional surgical procedures were evaluated herein. In addition, information about the type and number of implant-supported FDPs after implant placements were recorded.

\section{Statistical analysis}

Statistical analysis of data was performed using the SPSS 21.0 (IBM SPSS Inc., Armonk, NY, USA). Statistical package program. Descriptive data such as demographic data and dental implant numbers and locations were analyzed using the chi-square $\left(\mathrm{x}^{2}\right)$ test. Measurements were evaluated as arithmetic mean \pm standard deviation. The significance level for all statistical analysis was considered as $p<.05$.

\section{Results}

Figure 1 shows the demographic data of the patients. The mean age of these patients was determined to be $49.61 \pm 11.84$ years. Most patients with dental implants were in the 51-60 age group, while patients with the least number of placed implants were in the 18-30 age group (Fig. 1).

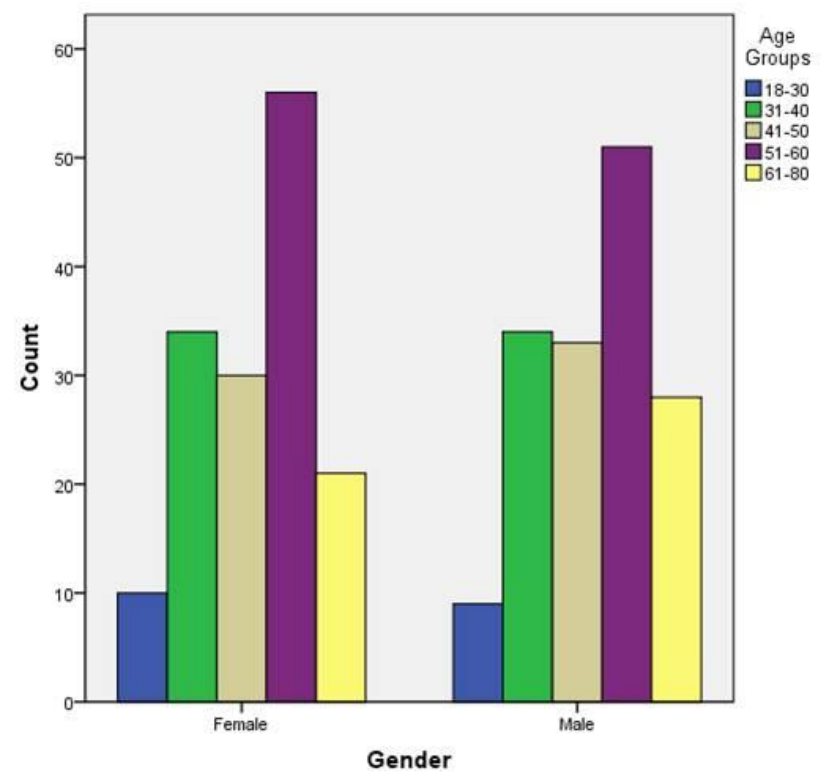

Figure 1. Distribution of dental implants according to age groups and gender. 
Figure 2 shows the distribution of the applied implants according to the age groups and missing teeth in the jaws. Dental implants were mostly applied to jaws with tooth-end and free-end partial edentulous, and these implants were mostly observed in the 51-60 age group. In addition, dental implants were at least applied to patients with total edentulism (Fig. 2).

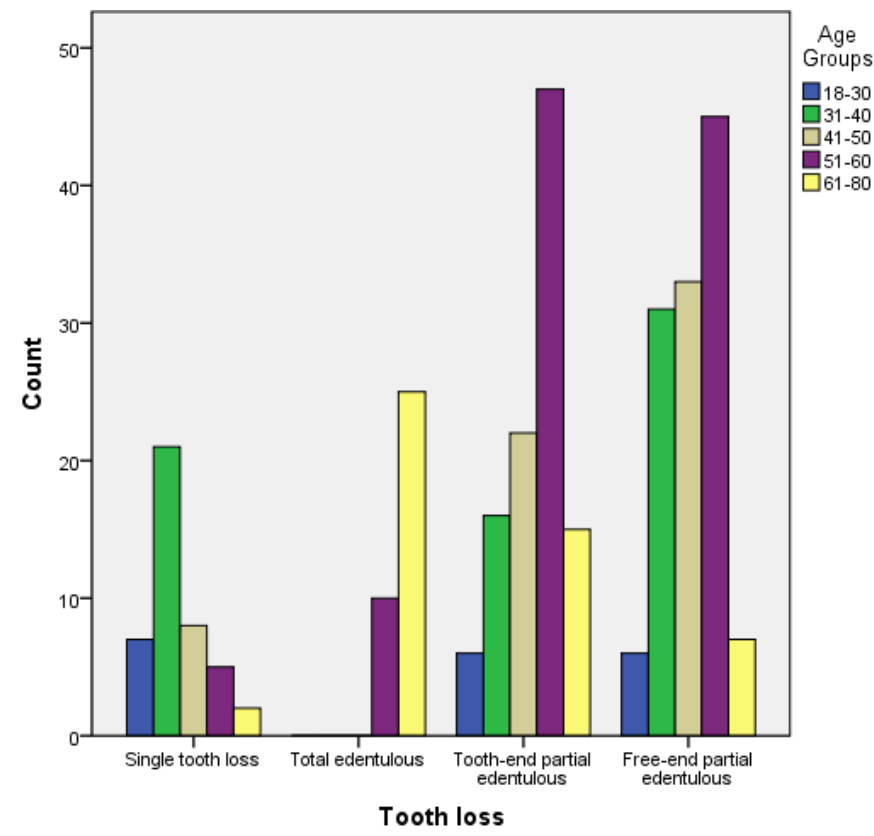

Figure 2. Distribution of the number of applied dental implants according to tooth loss and age groups.
Table 1 summarizes the distribution of dental implants according to their diameter, length, survival, and additional surgical procedures. With respect to the implant length, in terms of implant length, $71.2 \%$ of dental implants corresponded to the middle implant length, and $11.4 \%$ corresponded to the short implant length. With respect to implant diameters, $64.4 \%$ of the middle implant diameters were used, and $94.8 \%$ of the dental implants were found to be successful. In the application of dental implants to the patients, $26.1 \%$ grafts and membranes were used as additional surgical procedures.

Table 2 summarizes the distribution of dental implants according to the type of restoration, implant location, and abutment type. LSMC were the most applied $57.8 \%$ in implant-supported FDPs, predominantly to the posterior maxilla $38.9 \%$. Straight abutments were applied in $80.7 \%$ of implant-supported FDPs.

Table 3 lists the distribution of dental implants in age groups according to the type of restoration. A significant difference was observed among the age groups with LSMC and all-ceramics $(\mathrm{p}<0.05)$. In implantsupported FDPs, $43.5 \%$ of LSMC was applied in the 51 60 age groups, while $53.13 \%$ of all-ceramics was applied in the $31-40$ age group.

Table 1. Distribution of dental implants according to diameter, length, survival, and additional surgical procedures.

\begin{tabular}{|c|c|c|c|}
\hline & & $\begin{array}{l}\text { Number of } \\
\text { Implants }\end{array}$ & Percentage (\%) \\
\hline \multirow{3}{*}{ Implant length } & Short $(X<10 \mathrm{~mm})$ & 35 & 11.4 \\
\hline & Middle $(10 \leq X \leq 12 \mathrm{~mm})$ & 218 & 71.2 \\
\hline & Long (12 mm<X) & 53 & 17.3 \\
\hline \multirow{3}{*}{$\begin{array}{l}\text { Implant } \\
\text { diameter }\end{array}$} & Narrow $(3 \leq X<4 \mathrm{~mm})$ & 60 & 19.6 \\
\hline & Middle $(4 \leq X \leq 4.5 \mathrm{~mm})$ & 197 & 64.4 \\
\hline & Large $(4.5 \mathrm{~mm}<\mathrm{X})$ & 49 & 16.0 \\
\hline \multirow{2}{*}{ Implant survival } & Successful & 290 & 94.8 \\
\hline & Failed & 16 & 5.2 \\
\hline \multirow{3}{*}{$\begin{array}{l}\text { Additional } \\
\text { surgical } \\
\text { procedure }\end{array}$} & No surgical procedure was performed & 205 & 67.0 \\
\hline & Graft & 21 & 6.9 \\
\hline & Graft and Membrane & 80 & 26.1 \\
\hline
\end{tabular}


Table 2. Distribution of dental implants according to patients in terms of restoration type, location, and abutment type.

\begin{tabular}{|c|c|c|c|}
\hline & & Total & Percentage (\%) \\
\hline \multirow{4}{*}{$\begin{array}{l}\text { Restoration } \\
\text { type }\end{array}$} & Laser sintered metal-ceramic & 177 & 57.8 \\
\hline & Cast metal-ceramic & 57 & 18.6 \\
\hline & Zirconia-ceramic & 40 & 13.1 \\
\hline & All-ceramic & 32 & 10.5 \\
\hline \multirow{6}{*}{$\begin{array}{l}\text { Implant } \\
\text { location }\end{array}$} & Anterior maxilla & 30 & 9.8 \\
\hline & Posterior maxilla & 119 & 38.9 \\
\hline & Anterior mandibula & 49 & 16.0 \\
\hline & Posterior mandibula & 108 & 35.3 \\
\hline & Maxilla & 156 & 51.0 \\
\hline & Mandibula & 150 & 49.0 \\
\hline \multirow{3}{*}{ Abutment type } & Straight & 247 & 80.7 \\
\hline & Angled & 12 & 3.9 \\
\hline & Custom & 47 & 15.4 \\
\hline
\end{tabular}

Table 3. Distribution of dental implants according to the type of restoration.

\begin{tabular}{|c|c|c|c|c|c|c|c|}
\hline \multirow{2}{*}{$\begin{array}{c}\text { Restoration } \\
\text { type }\end{array}$} & \multicolumn{5}{|c|}{ Age groups(n) } & \multirow{2}{*}{ Total } & \multirow{2}{*}{ p-value } \\
\hline & $18-30$ & $31-40$ & $41-50$ & $51-60$ & $61-80$ & & \\
\hline $\begin{array}{c}\text { Laser } \\
\text { sintered } \\
\text { metal-ceramic }\end{array}$ & $13(7.34)$ & $36(20.34)$ & $36(20.34)$ & $77(43.5)$ & $15(8.47)$ & 177 & $<0.001^{*}$ \\
\hline $\begin{array}{l}\text { Cast metal- } \\
\text { ceramic }\end{array}$ & $2(3.51)$ & $10(17.54)$ & $17(29.82)$ & $16(28.07)$ & $12(21.1)$ & 57 & 0.078 \\
\hline $\begin{array}{l}\text { Zirconia- } \\
\text { ceramic }\end{array}$ & $8(20)$ & $12(30)$ & $14(35)$ & $4(10)$ & $2(5)$ & 40 & 0.215 \\
\hline All-ceramic & $4(12.5)$ & $17(53.13)$ & $3(9.38)$ & $6(18.75)$ & $2(6.25)$ & 32 & $<0.001^{*}$ \\
\hline
\end{tabular}

Table 4 lists the distribution of dental implants in age groups according to the abutment type. A statistically significant difference was observed in age groups among straight, angled, and custom abutments $(\mathrm{p}<.05)$. In abutment types, straight and angled abutments were used in the 51-60 age groups $(34.8 \%$ and $34 \%$, respectively), while custom abutments were used in $50 \%$ of the $31-40$ age groups.

Table 5 lists the distribution of dental implants according to implant location. A significant difference was observed among dental implant location and age groups $(\mathrm{p}<.05)$. Dental implants were mostly applied to the maxilla, predominantly in the posterior maxilla, and $31.9 \%$ of dental implants were applied to the $51-60$ age group. At least dental implants were applied to the anterior maxilla region, and dental implants were not applied to the anterior mandible region in the $18-30$ age group. 
Table 4. Distribution of dental implants in age groups according to the abutment type

\begin{tabular}{|c|c|c|c|c|c|c|c|}
\hline \multirow{2}{*}{$\begin{array}{c}\text { Abutment } \\
\text { type }\end{array}$} & \multicolumn{5}{|c|}{ Age groups $(n)$} & \multirow{2}{*}{ Total } & \multirow{2}{*}{ p-value } \\
\hline & $18-30$ & $31-40$ & $41-50$ & $51-60$ & $61-80$ & & \\
\hline Straight & $16(6.48)$ & $55(22.3)$ & $52(21.1)$ & $86(34.8)$ & $38(15.4)$ & 247 & $0.004^{*}$ \\
\hline Angled & $3(6.4)$ & $7(14.9)$ & $10(21.3)$ & $16(34.0)$ & $11(23.0)$ & 47 & 0.316 \\
\hline Custom & 0 & $6(50.0)$ & $1(8.3)$ & $5(41.7)$ & 0 & 12 & $<0.001^{*}$ \\
\hline
\end{tabular}

Table 5. Distribution of dental implants according to the location.

\begin{tabular}{|c|c|c|c|c|c|c|c|}
\hline \multirow{2}{*}{$\begin{array}{l}\text { Implant } \\
\text { Location }\end{array}$} & \multicolumn{5}{|c|}{ Age groups $(n)$} & \multirow{2}{*}{ Total } & \multirow{2}{*}{ p-value } \\
\hline & $18-30$ & $31-40$ & $41-50$ & $51-60$ & $61-80$ & & \\
\hline $\begin{array}{l}\text { Anterior } \\
\text { maxilla }\end{array}$ & $2(6.7)$ & $4(13.3)$ & $5(16.7)$ & $19(63.3)$ & 0 & 30 & $<0.001^{*}$ \\
\hline $\begin{array}{l}\text { Posterior } \\
\text { maxilla }\end{array}$ & $11(9.2)$ & $32(26.9)$ & $30(25.2)$ & $38(31.9)$ & $8(6.7)$ & 119 & $0.016^{*}$ \\
\hline $\begin{array}{l}\text { Anterior } \\
\text { Mandibula }\end{array}$ & 0 & $3(6.1)$ & $2(4.1)$ & $19(38.8)$ & $25(51.0)$ & 49 & $0.039^{*}$ \\
\hline $\begin{array}{l}\text { Posterior } \\
\text { Mandibula }\end{array}$ & $6(5.6)$ & $29(26.9)$ & $26(24.1)$ & $31(28.7)$ & $16(14.8)$ & 108 & $0.025^{*}$ \\
\hline Maxilla & $13(8.3)$ & $39(25.0)$ & $37(23.7)$ & $59(37.8)$ & $8(5.1)$ & 156 & $<0.001^{*}$ \\
\hline Mandibula & $6(4.0)$ & $29(19.3)$ & $26(17.3)$ & $48(32.0)$ & $41(27.3)$ & 150 & $0.003^{*}$ \\
\hline
\end{tabular}

\section{Discussion}

According to the results of this study, the highest number of dental implant applications was observed in the 51-60 age group, and the most common edentulous was tooth-end partial edentulism. In addition, the predominant dental implant location was the posterior region of the maxilla, and the length and diameter of the most commonly used dental implants were 10-12 $\mathrm{mm}$ and 4-4.5 $\mathrm{mm}$, respectively. In addition, straight abutment and LSMC were mostly applied in implantsupported FDPs.

Currently, dental implants have been successfully applied to replace lost teeth for any reason. Owing to the effective and predictable results observed with dental implants, they are utilized by physicians as an alternative to conventional tooth-supported prostheses. The risk of tooth loss increases with age due to alveolar bone, dental caries, periodontal disease, and some systemic diseases. However, tooth losses increase the need for dental implant treatment. In a demographic study, Vehemente et al. (8) reported an average age of 53.5 and an age range of 16-92. Urvasızoğlu et al. (1) reported a mean age of 41.1 and an age range of 46-55. Yildirim et al. (9) reported an age range of 41-50. In contrast to these studies, in the present study, the most frequent dental implants were observed in patients with an average age of 49.6 and an age range of 51-60.

When the edentulous status was examined according to the indication of the patients, Tulstunov (10) reported that the most common dental implants were applied to the total edentulous in the mandible. In another study, Urvasizoglu et al. (1) reported that the most common dental implants were applied to 
partially edentulous patients. In this study, unlike that conducted by Tulstunov (10), dental implants were applied to partially edentulous patients with toothend, similar to the study conducted by Urvasizoglu et al (1). Owing to the relatively high dental implant treatment costs and excessive resorption of the alveolar bone in advanced ages, it may have affected the low number of dental implants applied to total edentulous patients in this study.

Loss of teeth due to decay and periodontal diseases is more common in posterior teeth due to insufficient brushing of teeth due to the location and occlusal morphology of the teeth in the posterior regions, especially as the first molar teeth are the earliest permanent teeth. Vehemente et al. (8) reported that the most common location for the application of dental implants was the posterior region. Urvasizoglu et al. (1) reported that $60 \%$ of the dental implants were applied to the posterior region. Yildirim et al. (9) and Polat et al. (11) reported that $67.2 \%$ and $71.7 \%$ of dental implants were applied to the posterior region, respectively. Similar to these studies, in the present study, $74.2 \%$ of the dental implants were applied to the posterior region.

The length and diameter of dental implants are crucial for primary stability due to the bone-implant contact surface (12). In addition, some studies reported that the implant length and diameter affect the clinical lifespan of the implant $(13,14)$. Urvasizoglu et al. (1), Polat et al. (11), and Oz et al. (15) reported that dental implants with a 12-mm length as well as a medium diameter were applied the most. In this study, parallel to the above studies, dental implants were found to exhibit the highest proportion of medium length (10-12 $\mathrm{mm})$ and narrow diameter $(4-4.5 \mathrm{~mm}) \quad(71.2 \%$ and $64.4 \%$, respectively).

Previous studies evaluated the success and failure rates of dental implants according to several criteria. Owing to the result of a 5-year follow-up, the survival rate of dental implants was found to be $>95 \%$ (16). Eltaș et al. (5) reported a dental implant survival rate of 97.4\%. Similar to these two studies, the survival rate of dental implants was $94.8 \%$ in this study.

In the area in which dental implants were applied, additional surgical procedures were required due to excessive alveolar bone loss as well as various trauma and pathology-related defects. In this study, $6.9 \%$ grafts and $26.1 \%$ grafts and membranes were applied in addition to dental implant surgical operations. According to the study conducted by Polat et al. (11), additional grafting was applied at a lower rate in this study. This situation may be related to different patient populations and sample sizes.

Currently, several materials are used in implantsupported FDPs, and the most commonly used material is conventional cast metal-ceramic. In addition to technological developments, the use of LSMC and tooth-colored restorations (zirconia-ceramic and allceramic) is increasing due to their production and design advantages (17). In this study, the highest amount of LSMC $57.8 \%$ were used for prosthetic restorations of patients with dental implants and most patients in the 51-60 age group. The least applied restoration type was all-ceramic $10.5 \%$. In this study, when evaluated in terms of the abutment type of implant-supported FDPs, the highest proportion of straight abutments were applied $80.7 \%$. The application of straight abutments can often indicate whether clinicians performing implant surgery have placed the implant most accurately.

\section{Conclusions}

In dentistry, dental implant treatment is considered as a treatment option that is increasingly important and used as a gold standard for the treatment of tooth loss. In this study, dental implant placements were performed more frequently in male patients and in the 51-60 age group. More dental implants were applied in the posterior maxilla with tooth-end according to the indication of missing tooth condition. Although the survival rate of implants was high, the frequently used length and diameter of the implants were $10-12 \mathrm{~mm}$ and $4-4.5 \mathrm{~mm}$, respectively. Laser-sintered metal-ceramics and straight abutments are the most commonly used in implant-supported FDPs. This retrospective study provides valuable information to clinicians practicing dental implants. Comprehensive and multi-center studies are required for a healthy analysis of the data obtained in this study.

Ethical Approval: Ethics committee approval was received for this study from Adiyaman University, Ethics Committee in accordance with the World Medical Association Declaration of Helsinki, with the approval number: 2020/3-13).

Peer-review: Externally peer-reviewed.

Author Contributions: Conception - F.D.; Design - A.T., F.D.; Supervision - A.T.; Materials - F.D., A.T.; Data Collection and/or Processing - F.D., A.T.; Analysis and/or Interpretation - A.T.; Literature Review - F.D., A.T.; Writer - F.D.; A.T.; Critical Review F.D.

Conflict of Interest: No conflict of interest was declared by the authors.

Financial Disclosure: The authors declared that this study has received no financial support.

\section{References}

1. Urvasızoğlu, Gelengül Gürbüz; Saruhan, Nesrin; Ataol, Mert. Evaluation Of Demographic And Clinical Features Of Dental Implant Applications. J Dent Fac Atatürk Uni, 2016;26(3):394398.

2. Esposito M, Barausse C, Pistilli R, Sammartino G, Grandi G, Felice P. Short implants versus bone augmentation for placing longer implants in atrophic maxillae: One-year post-loading results of a pilot randomised controlled trial. Eur J Oral Implantol. 2015;8(3):257-68.

3. Yaltırık M and Alen P. All Aspects of Single Tooth Dental Implant Planning and Applications. Turkiye Klinikleri J Oral Maxillofac Surg-Special Topics 2015;1(2):27-32.

4. Carcuac O, Jansson L. Peri-implantitis in a specialist clinic of 
periodontology. Clinical features and risk indicators. Swed Dent J. 2010;34: 53-61.

5. Eltas A, Dundar S, Uzun IH, Malkoç MA. Assesement of Dental Implant Success and Patient Profile: A Retrospective Study. J Dent Fac Atatürk Uni, 2013;23(1):1-8.

6. Spiekermann H, Jansen VK, Richter EJ. A 10-year follow-up study of IMZ and TPS implants in the edentulous mandible using bar-retained overdentures. Int J Oral Maxillofac Implants. 1995; 10:231-43.

7. Mericske-Stern R, Steinlin Schaffner T, Marti P, Geering AH. Peri-implant mucosal aspects of ITI implants supporting overdentures. A five-year longitudinal study. Clin Oral Implants Res. 1994;5(1):9-18. (Crossref)

8. Vehemente VA, Chuang SK, Daher S, Muftu A, Dodson TB. Risk factors affecting dental implant survival. J Oral Implantol. 2002;28(2):74-81. (Crossref)

9. Yildirim Guler, et al. Demographic evaluation of implant locations among 1000 adult patients in Turkey. Avicenna Journal of Dental Research 2018;10(1):22-27. (Crossref)

10. Tolstunov L. Implant zones of the jaws: implant location and related success rate. J Oral Implantol. 2007;33(4):21120. (Crossref)

11. Polat ME, Saruhan N, Gojayeva, G. The Demographic Evaluation of Dental Implant Patients. Journal of Biotechnology and Strategic Health Research, 2019;3(2):8590.
12. Rignon-Bret C, Wulfman C, Hadida A, Renouard F, Gourraud PA, Naveau A. Immediate Loading of Two Unsplinted Implants in Edentulous Patients with Mandibular Overdentures: A 10year Retrospective Review of Patients from a Previously Conducted 1-year Cohort Study. Int J Oral Maxillofac Implants. 2019;34(1):169-178. (Crossref)

13. Jemt T, Lekholm U. Implant treatment in edentulous maxillae: a 5-year follow-up report on patients with different degrees of jaw resorption. Int J Oral Maxillofac Implants. 1995;10:30311.

14. Shin SW, Bryant SR, Zarb GA. A retrospective study on the treatment outcome of wide-bodied implants. Int $\mathrm{J}$ Prosthodont 2004;17:52-8.

15. Oz OP, Demirkol N. A retrospective analysis of dental implants in patients who received a mandibular overdenture with locator attachment. Ann Med Res. 2019;26(12):2841-6. (Crossref)

16. Balaguer-Martí JC, Peñarrocha-Oltra D, Balaguer-Martínez J, Peñarrocha-Diago $\mathrm{M}$. Immediate bleeding complications in dental implants: a systematic review. Med Oral Patol Oral Cir Bucal. 2015;20(2):e231-8. (Crossref)

17. Cho $\mathrm{Y}$, Raigrodski AJ. The rehabilitation of an edentulous mandible with a CAD/CAM zirconia framework and heatpressed lithium disilicate ceramic crowns: a clinical report. J Prosthet Dent. 2014;111(6):443-7. (Crossref) 